\title{
A large real-world cohort study of examined lymph node standards for adequate nodal staging in early non-small cell lung cancer
}

\author{
Zhihua Zhu ${ }^{1 \#}$, Zhengbo Song ${ }^{2 \#}$, Wenjie Jiao ${ }^{3 \#}$, Weijian Mei ${ }^{1}$, Chunwei Xu' ${ }^{4}$,inghua Huang ${ }^{5}$, Chaolun An ${ }^{6}$, \\ Jianguang Shi ${ }^{7}$, Wenxian Wang ${ }^{2}$, Guiping Yu ${ }^{8}$, Pingli Sun ${ }^{9}$, Yinbin Zhang ${ }^{10}$, Jianfei Shen ${ }^{11}$, Yong Song ${ }^{12}$, \\ Jun Qian ${ }^{13}$, Wang Yao ${ }^{14}$, Han Yang ${ }^{1}$; written on behalf of AME Lung Cancer Collaborative Group
}

${ }^{1}$ Sun Yat-sen University Cancer Center; State Key Laboratory of Oncology in South China; Collaborative Innovation Center for Cancer Medicine, Guangzhou, China; ${ }^{2}$ Cancer Hospital of University of Chinese Academy of Sciences; Zhejiang Cancer Hospital, Hangzhou, China; ${ }^{3}$ Affiliated Hospital of Qingdao University, Qingdao, China; ${ }^{4}$ Fujian Cancer Hospital, Fuzhou, China; ${ }^{5}$ Affiliated Tumor Hospital of Guangxi Medical University, Nanning, China; ${ }^{6}$ Nantong Third People's Hospital, Nantong University, Nantong, China; ${ }^{7}$ Ningbo First Hospital of Zhejiang University, Ningbo, China; ${ }^{8}$ Affiliated Jiangyin Hospital of Southeast University, Jiangyin, China; ${ }^{9}$ The Second Hospital of Jilin University, Changchun, China; ${ }^{10}$ The Second Affiliated Hospital of Medical College, Xi'an Jiaotong University, Xi'an, China; ${ }^{11}$ Taizhou Hospital of Zhejiang Province, Wenzhou Medical University, Linhai, China; ${ }^{12}$ Affiliated Jinling Hospital, Medical School of Nanjing University, Nanjing, China; ${ }^{13}$ Southern Medical University, Guangzhou, China; ${ }^{14}$ The First Affiliated Hospital, Sun Yat-sen University, Guangzhou, China Contributions: (I) Conception and design: W Yao, Z Zhu; (II) Administrative support: Z Song, W Jiao, C Xu, Q Huang, C An, J Shi, G Yu, P Sun, Y Zhang, J Shen; (III) Provision of study materials or patients: H Yang; (IV) Collection and assembly of data: W Mei; (V) Data analysis and interpretation: J Qian, Y Song; (VI) Manuscript writing: All authors; (VII) Final approval of manuscript: All authors.

\#These authors contributed equally to this work.

Correspondence to: Jun Qian, PhD. School of Biomedical Engineering, Southern Medical University, 1023 Shatainan Road, Guangzhou 510515, China. Email: qianjun_gz@126.com; Dr. Wang Yao, MD. The First Affiliated Hospital, Sun Yat-sen University, 58 Zhongshan Second Road, Guangzhou 510060, China. Email: yaow7@mail.sysu.edu.cn; Dr. Han Yang, MD, PhD. Sun Yat-sen University Cancer Center; State Key Laboratory of Oncology in South China; Collaborative Innovation Center for Cancer Medicine, 651 Dongfeng Road East, Guangzhou 510060, China.

Email: yanghan@sysucc.org.cn.

Background: The current National Comprehensive Cancer Network (NCCN) guidelines for non-small cell lung cancer (NSCLC) recommend that surgeons sample is not clear. We aimed to define a minimal number of examined lymph nodes for removal or sampling for optimized nodal staging recommendation, with a focus on $\mathrm{T}_{1-3} \mathrm{~N}_{0} \mathrm{M}_{0}$ patients.

Methods: A total of 55,101 consecutive patients were selected, including 52,099 patients with US Surveillance, Epidemiology, and End Results (SEER) data and 3,002 patients in a Chinese multicenter database from 11 thoracic referral centers, who underwent complete resection plus lymph node dissection or sampling for stage $\mathrm{T}_{1-3} \mathrm{~N}_{0} \mathrm{M}_{0}$ NSCLC. Propensity score-matching analysis was performed with R software, and a cut-off value was calculated using X-tile software. Survival was evaluated using the Kaplan-Meier method and Cox proportional hazard models.

Results: Five-year survival rates with respect to total examined lymph nodes numbers (examined lymph nodes $<10$ vs. examined lymph nodes $\geq 10$ ) were $69 \%$ and $64 \%$ (group A), 66\% and 63\% (group B), 62\% and $58 \%$ (group C), $81 \%$ and $75 \%$ (group D). There were significant differences between examined lymph nodes $<10$ and examined lymph nodes $>10$ in each group $(\mathrm{P}<0.001)$.

Conclusions: A minimum of 10 examined lymph nodes would significantly improve $\mathrm{T}_{1-3} \mathrm{~N}_{0} \mathrm{M}_{0}$ NSCLC prognosis and patients' survival rates if implemented as a minimum standard for lymphadenectomy. Therefore, we recommended a minimum of 10 examined lymph nodes for $\mathrm{T}_{1-3} \mathrm{~N}_{0} \mathrm{M}_{0}$ patients.

Keywords: Non-small cell lung cancer (NSCLC); examined lymph node (ELN); minimal number; nodal staging; cohort study 
Submitted Sep 06, 2020. Accepted for publication Dec 23, 2020.

doi: $10.21037 /$ tlcr-20-1024

View this article at: http://dx.doi.org/10.21037/tlcr-20-1024

\section{Introduction}

Lung cancer remains the most significant solid malignancy with high cancer-related mortality (1). For early-stage non-small cell lung cancer (NSCLC), radical resection plus lymph node dissection or sampling of high quality is the current standard of care. However, the 5 -year overall survival (OS) after surgery is only between $50 \%$ and $60 \%$ (2), and locoregional recurrence and/or distant metastasis account for the majority of failures. Accurate prognosis and prediction therefore rely on adequate staging information. Lymph node staging is one of the most important factors determining the prognosis of resected NSCLC and is a multi-step strategy that depends on tumor factors including size, location related to the hilum and the lobe involved, and radiologic suspicion for nodal disease. Pathologic lymph node $(\mathrm{pN})$ assessment is more accurate than clinical assessment (3), and the thoroughness of $\mathrm{pN}$ examination affects the prognostic value $(4,5)$. Lung cancer patients with mediastinal lymph node involvement (N2) or hilar lymph node involvement (N1) may be frequently misdiagnosed as node-negative (N0) since pathological examination factors are variable, such as inadequate sampling of the hilar lymph nodes or intrapulmonary lymph nodes after radical surgery.

For some cancers, National Comprehensive Cancer Network (NCCN) guidelines recommend the minimal number of examined lymph nodes (ELNs) for removal or sampling for adequate nodal staging; for example, gastric cancer (6) diagnoses require examination of at least 15 or greater ELNs and colon cancer (7) guidelines call for a minimum of 12 ELNs for the examination to accurately establish $\mathrm{N}$ stage. However, the current NCCN guidelines for NSCLC recommend that surgeons sample only the lymph node stations and states that one or more nodes should be sampled from all mediastinal stations (4L, 5, 6, 7, 8 , and 9 for left-side; 2R, 4R, 7, 8, and 9 for right-side) (8). Several previous studies have also shown a correlation between the number of ELNs and long-term survival (9-15). Liang et al. recommended 16 ELNs as the cut-off point for evaluating the quality of lymph node examination or prognostic stratification for patients with declared nodenegative resected NSCLC (16). However, our research found that the above criteria could not be supported by a larger sample and too many patients in these studies. Apparently, the ELN count remains controversial.

Based on the Surveillance, Epidemiology, and End Results (SEER) database and a large cohort from the China multi-center retrospective database, the study was designed to provide an in-depth understanding into the optimal number of ELNs and for NSCLC diseases. Our study was divided into two parts. In this part, the largest number of patients for a study of this nature were recruited to analyze the number of ELNs and discover any potential correlations with long-term survival. And we would discuss the location of the lymph node in the part II. We present the following study in accordance with the STROBE reporting checklist (available at http://dx.doi.org/10.21037/tlcr-20-1024).

\section{Methods}

The study was conducted in accordance with the Declaration of Helsinki (as revised in 2013). The study was approved by committee board of 11 participating institutions and individual consent for this retrospective analysis was waived (NO. 2019—0810)

\section{Patients}

SEER database: NSCLC cases were obtained from the National Cancer Institute SEER program data, including group A (2010/01/01-2013/10/31) staged with the $7^{\text {th }}$ edition of the TNM classification; group B (2004/01/01$2009 / 12 / 31)$ staged with the $6^{\text {th }}$ edition of the TNM classification and group C (1988/01/01-2003/12/31) staged with the $3^{\text {th }}$ edition of the TNM classification. It's hard to migrate them into the $8^{\text {th }}$ edition of the TNM classification because of the incomplete pathological information such as tumor extension in SEER database. Group A was deemed as the modeling group to calculate the cut-off values of ELNs while group B and group C were deemed as validation groups. All patients were uniformly reviewed and staged according to the seventh edition of the TNM classification.

Chinese multi-institutional retrospective database (group D): a multi-institutional registry of consecutively collected data on patients with NSCLC who underwent 
surgical resection between January 1999 and October 2013 at the departments of thoracic surgery of 11 institutions in China (Sun Yat-sen University Cancer Center, Guangzhou; Zhejiang Cancer Hospital, Hangzhou; Affiliated Hospital of Qingdao University, Shandong Province; Affiliated Tumor Hospital of Guangxi Medical University, Nanning; Fujian Cancer Hospital, Fujian Medical University, Fuzhou; the Second Affiliated Hospital of Medical College, Xi'an Jiaotong University, Shanxi Province; Taizhou First People's Hospital, Zhejiang Province; Third People's Hospital of Nantong City, Jiangsu Province; Ningbo First Hospital, Ningbo Hospital of Zhejiang University, Zhejiang Province; Affiliated Jiangyin Hospital of Southeast University, Jiangsu Province; the Second Hospital of Jilin University, Jilin Province) was used for the analyses (original data are provided in Supplementary appendix). Group D was the validation group with all the data included. Ethical approval was obtained from participating institutions through their respective institutional review boards. In cases in which individual patient's consent was not identified, the chairperson of the ethics committee waived the need for patient consent. These patients were staged using the $8^{\text {th }}$ edition of the TNM classification. The lymph nodes included those dissected during surgical resection and those re-sampled by the surgeon after surgery. The final lymph nodes number was determined by the pathologist.

\section{Inclusion and exclusion criteria}

Eligible patients in this study: (I) were diagnosed with NSCLC histologically and pathological staged of $\mathrm{T}_{1-3} \mathrm{~N}_{0} \mathrm{M}_{0}$ according to the NCCN TNM classification; (II) underwent complete (R0) resection plus lymph node dissection or sampling, and had at least one lymph node that was harvested and examined; (III) had at least 5 years of follow-up. Exclusion criteria included: (I) a history of prior synchronous or metachronous malignancies; (II) presurgery chemotherapy, radiation, target therapy, and any other anti-tumor therapy; (III) positive resection margins and palliative surgery: sublobectomy, segmentectomy, or wedge-shaped lobectomy; (IV) mortality within 30 days.

\section{Calculation of cut-off value for ELNs}

For this study, X-tile plots were created by dividing ELNs data into low and high populations, with all possible divisions of ELNs data assessed. A variety of standard statistical tests were applied to calculate associations of each division, including the log-rank survival test and means tests for between ELNs associations. A graphical illustration of the data was presented in a right-triangular grid with each point (pixel) representing the data from a given set of divisions. All the possible "high" populations were presented in the vertical axis with the size increasing from top to bottom. Conversely, all the possible "low" populations were presented in the horizontal axis with the size increasing from left to right. Results from a single cutoff point which divided the data into high or low subsets were presented along the hypotenuse. Survival curves could be generated when the user moved the cursor over any cutoff point. Alternatively, automatic selection of the highest $\chi^{2}$ value could also present the optimal division of data. To assess statistical significance, a standard log-rank test was applied with $\mathrm{P}$ values obtained from a lookup table (17) and the cut-off point derived from a training set to parse a separate validation set.

Survival analysis was performed after propensity score matching (PSM) analysis in order to adjust potential biases by selecting statistical difference variables in the propensity model. The selected variables in the propensity model included age, gender, T-staging, histological type, race, marital status, and histological grade. In this study, lymph node dissection followed the protocol as illustrated by Liang et al. (16).

\section{Follow-up}

OS was the only outcome variable considered in our study. Follow-up information of SEER could be obtained directly from a database, and information from 11 institutions in China were completed by staff of hospitals using telephone correspondence. All patients were followed and death or arrival of follow-up period were considered as the ending point. The final follow-up date was October 31, 2018.

\section{Statistical analysis}

Categorical variables were presented as frequency (\%), and continuous variables as median (interquartile range). Population characteristics were compared using the Pearson's chi-square test for categorical variables and the independent $t$-test (or Mann-Whitney U-test) for continuous variables. The PSM analysis was performed using R software (TIBCO, Silicon Valley, CA, USA). The cut-off value was calculated by $\mathrm{X}$-tile software version 3.6.1 (Yale University, New Haven, CT, USA) (17). Survival 
data were calculated using the Kaplan-Meier method and compared using a log-rank test. Univariate and multivariate survival analyses were conducted using the Cox proportional hazards regression method. The Kaplan-Meier method and log-rank tests were used to estimate OS, and hazard ratios (HRs) were calculated using the multivariate Cox regression analysis. All statistical analyses described above were performed with SPSS software (version 24.0 SPSS Inc., Chicago, IL, USA). A two-sided level of significance with a $\mathrm{P}$ value of less than 0.05 was used for all tests.

\section{Results}

\section{Baseline condition of selected patients}

The number of selected patients in this study were 12,423 (group A), 18,154 (group B), 21,522 (group C), and 3,002 (group D). Patients' deaths for group A, B, C, and D were 3,338 cases $(26.9 \%), 9,684$ cases $(53.3 \%), 17,469$ cases $(81.2 \%)$ and 721 cases $(24.0 \%)$, respectively. The median follow-up periods were 40 months (group A), 78 months (group B), 81 months (group C), and 65.9 months (group D) (Figure 1, Figures S1-S4 and Table 1).

The dominating ages of patients in groups $\mathrm{A}, \mathrm{B}$, and $\mathrm{C}$ were $\geq 65$ years, with proportions of $62.9 \%, 62.2 \%$, and $59.7 \%$, respectively. Group D was dominated by patients $<65$ years, with a proportion of $66.2 \%$. With insignificant gender differences, the proportion of males in groups A, B, and $\mathrm{C}$ were $52.4 \%, 51.2 \%$, and $46.0 \%$, respectively. Group $\mathrm{D}$ was predominately males with a proportion of $63.0 \%$. The dominating stages of all four groups were T1 and T2. For group A, the proportions of T1, T2, and T3 were $47.5 \%, 39.3 \%$, and $13.2 \%$, respectively. For group B, the proportions of $\mathrm{T} 1, \mathrm{~T} 2$, and $\mathrm{T} 3$ were $48.7 \%, 46.1 \%$, and $5.1 \%$, respectively. For group C, the proportions of T1, $\mathrm{T} 2$, and $\mathrm{T} 3$ were $43.9 \%, 50.1 \%$, and $6.0 \%$, respectively. For group D, the proportions of T1, T2, and T3 were $40.5 \%, 48.5 \%$ and $11.1 \%$, respectively. The dominating histological type of all four groups was adenocarcinoma with proportions of $61.1 \%$ (group A), $57.4 \%$ (group B), $55.1 \%$ (group C), and $64.3 \%$ (group D). The dominating race of groups $\mathrm{A}, \mathrm{B}$, and $\mathrm{C}$ was white with proportions of $82.8 \%$, $85.6 \%$ and $85.1 \%$, respectively. The proportions of married patients for groups $\mathrm{A}, \mathrm{B}$, and $\mathrm{C}$ were $56.3 \%, 59.4 \%$, and $62.2 \%$, respectively. For oncological classification, groups A and $\mathrm{B}$ were dominated by medium and high differentiation with proportions of $62.5 \%$ and $56.1 \%$, while group C had $37.6 \%$ unclear differentiation (Table S1).

\section{Lymph node excision}

For group A, 12,423 patients underwent 125,799 lymph node excisions, with a median of 8 (interquartile range 8 ). For group B, 18,154 patients underwent 161,854 excisions, with a median of 7 (interquartile range 8). For group C, 21,522 patients underwent 165,896 excisions, with a median of 6 (interquartile range 7). The location of lymph node in seer database was unclear. For group D, 3,002 patients underwent 50,849 excisions, with a median of 15 (interquartile range 12) (Figure S5).

\section{Demarcation of minimum quantity of lymph nodes}

Group A was selected as the exploration group given that it was the most current data and follow-up over 5 years. $\mathrm{X}$-tile software was used to determine that 10 was the most meaningful node. Internationally $\geq 6$ ELNs was generally recommended. Therefore, this study only focused on a cutoff rate $\geq 6$, testified with method of exhaustion (Table 1). According to Table 1, when 10 was the dividing line, the two groups had the most significant differences including the maximum chi-square value, relative risk $(\mathrm{RR})$ value, and the minimum $\mathrm{P}$ values.

\section{Baseline comparisons on ELNs $>10$ \& ELNs $<10$ (pre-PSM \& post-PSM)}

For accurate results, ELNs $>10$ and ELNs $<10$ were analyzed as baselines for each group. For group $\mathrm{B}$, gender $(\mathrm{P}=0.012)$, T-staging $(\mathrm{P}<0.001)$, histological type $(\mathrm{P}<0.001)$, race $(\mathrm{P}<0.001)$, and histological grade $(\mathrm{P}<0.001)$ expressed a maldistribution between the two groups. For group $\mathrm{C}$, age $(\mathrm{P}=0.034)$, gender $(\mathrm{P}<0.001)$, T-staging $(\mathrm{P}<0.001)$, histological type $(\mathrm{P}<0.001)$, race $(\mathrm{P}<0.001)$, marital status $(\mathrm{P}<0.001)$, and histological grade $(\mathrm{P}<0.001)$ expressed a maldistribution between the two groups. For group D, age $(\mathrm{P}=0.016)$, gender $(\mathrm{P}=0.045)$, T-staging $(\mathrm{P}<0.001)$, and histological type $(\mathrm{P}<0.001)$ expressed a maldistribution between the two groups. The maldistribution of influence factors between two groups could potentially affect the results (Table S2). For uneven baselines, PSM was applied for data processing to exclude confounding factors. To guarantee the largest sample size on even baselines, our study used different caliper values and matching for data of different groups.

For group B data, PSM model used 1:1 matching with 0.02 calipers. Altogether 6,348 matched successfully. After 


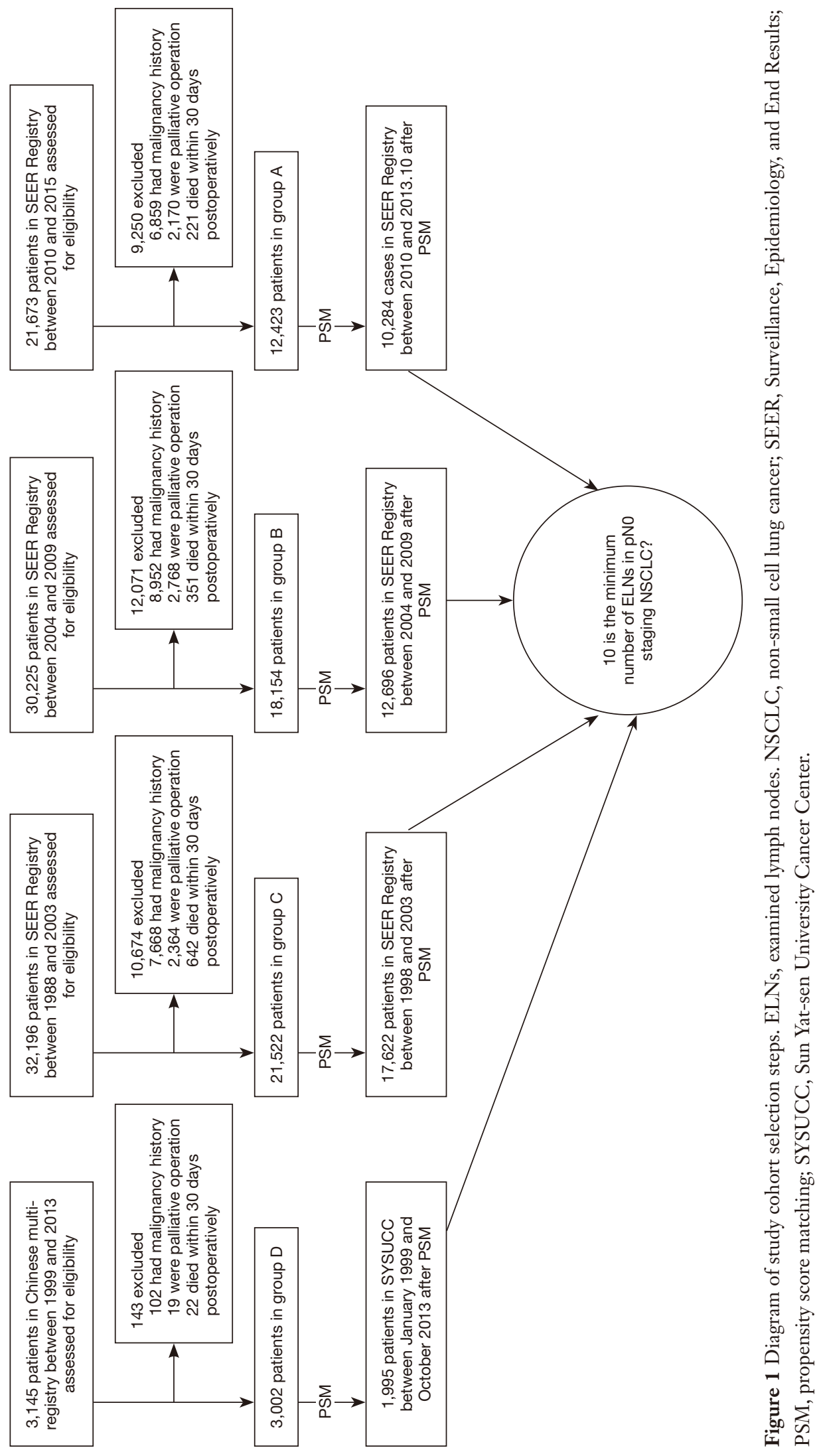


Table 1 Analysis of the cut-off value for ELNs

\begin{tabular}{lccc}
\hline Cut-off value for ELNs & Chi-square score & Relative risk & P value \\
\hline$<6$ vs. $\geq 6$ & 7.68 & 1.10 & 0.005 \\
$<7$ vs. $\geq 7$ & 5.63 & 1.08 & 0.018 \\
$<8$ vs. $\geq 8$ & 7.45 & 1.10 & 0.007 \\
$<9$ vs. $\geq 9$ & 7.00 & 1.10 & 0.008 \\
$<10$ vs. $\geq 10$ & 9.63 & 1.11 & 0.002 \\
$<11$ vs. $\geq 11$ & 3.45 & 1.08 & 0.065 \\
$<12$ vs. $\geq 12$ & 1.77 & 1.06 & 0.180 \\
$<13$ vs. $\geq 13$ & 2.46 & 1.07 & 0.114 \\
$<14$ vs. $\geq 14$ & 1.06 & 1.06 & 0.294 \\
$<15$ vs. $\geq 15$ & 0.41 & 1.05 & 0.527 \\
$<16$ vs. $\geq 16$ & 0.01 & 1.03 & 1.000 \\
$<17$ vs. $\geq 17$ & 0.01 & 1.03 & 1.000 \\
\hline
\end{tabular}

ELNs, examined lymph nodes.

matching, the age $(\mathrm{P}=0.143)$, gender $(\mathrm{P}=0.915)$, T-staging $(\mathrm{P}=0.738)$, histological type $(\mathrm{P}=0.787)$, race $(\mathrm{P}=0.838)$, marital status $(\mathrm{P}=0.765)$, and histological grade $(\mathrm{P}=0.538)$ expressed no statistical differences between two groups (Table S3).

For group C data, PSM model used 2:1 matching with 0.005 calipers. Altogether 5,874 matched successfully. After matching, the age $(\mathrm{P}=0.149)$, gender $(\mathrm{P}=0.389)$, $\mathrm{T}$-staging $(\mathrm{P}=0.265)$, histological type $(\mathrm{P}=0.090)$, race $(\mathrm{P}=0.224)$, marital status $(\mathrm{P}=0.670)$, and histological grade $(\mathrm{P}=0.729)$ expressed no statistical differences between two groups (Table S3).

For group D data, PSM model used 1:2 matching with 0.02 calipers. Altogether 665 matched successfully. After matching, the age $(\mathrm{P}=0.870)$, gender $(\mathrm{P}=0.538)$, T-staging $(\mathrm{P}=0.740)$, and histological type $(\mathrm{P}=0.880)$ expressed no statistical differences between two groups (Table S3).

\section{Post-PSM verification}

For group B, baselines were even between two groups with both accruing 6,348 matched cases after PSM. KaplanMeier result indicated that 10 ELNs was the factor affecting prognosis $(\mathrm{P}<0.001)$. See Figure 2 for survivorship curves for T1, T2, T3, and whole group. Patients with $\geq 10$ ELNs had better estimated median survival time (100 vs. 89 months, $\mathrm{P}<0.001), 3$-year survival rates $(78 \%$ vs. $75 \%, \mathrm{P}=0.001)$, 5 -year survival rates $(66 \%$ vs. $63 \%, \mathrm{P}<0.001)$ than patients with $<10$ ELNs (Figure 3). Cox regression indicated that ELNs cut-off point 10 was independent prognostic factor (HR, 0.871; 95\% CI, 0.831-0.914; $\mathrm{P}<0.001$ ) (Table S4).

For group C, baselines were even between two groups with 11,748 and 5,874 matched cases after PSM. KaplanMeier result indicated that 10 ELNs was the factor affecting prognosis $(\mathrm{P}<0.001)$. See Figure 2 for survivorship curves for T1, T2, T3, and whole group. Patients with $\geq 10$ ELNs had better estimated median survival time (89 vs. 79 months, $\mathrm{P}<0.001)$, 3-year survival rates $(74 \%$ vs. $71 \%, \mathrm{P}<0.001)$, 5 -year survival rates $(62 \%$ vs. $58 \%, \mathrm{P}<0.001)$ than patients with $<10$ ELNs (Figure 3). Cox regression indicated that ELNs cut-off point at 10 was independent prognostic factor (HR, 0.888; 95\% CI, 0.858-0.920; $\mathrm{P}<0.001$ ) (Table S4).

For group D, baselines were even between two groups with 665 and 1,330 matched cases after PSM. Kaplan-Meier result indicated that 10 ELNs was the factor affecting prognosis $(\mathrm{P}<0.001)$. See Figure 2 for survivorship curves for T1, T2, T3, and whole group. Patients with $\geq 10$ ELNs had better 5 -year survival rates $(81 \%$ vs. $75 \%, \mathrm{P}=0.002)$ than patients with $<10$ ELNs (Figure 3). Cox regression indicated that 10 ELNs was independent prognostic factor (HR, 0.693; 95\% CI, 0.579-0.830; P<0.001) (Table S4).

\section{Discussion}

Adequate intra-operative lymphadenectomy was a fundamental component of lung cancer surgery. ELNs 


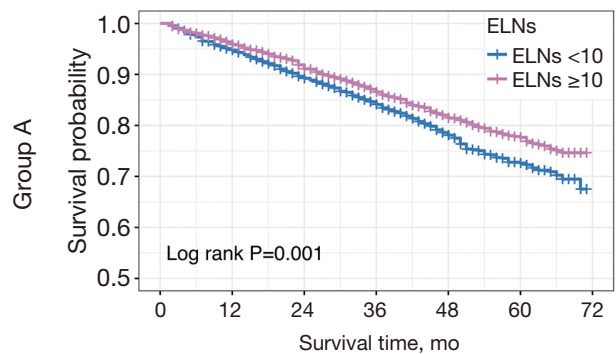

Number at risk
T2

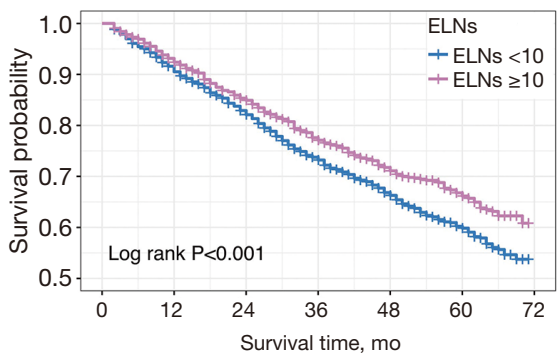

Number at risk
T3

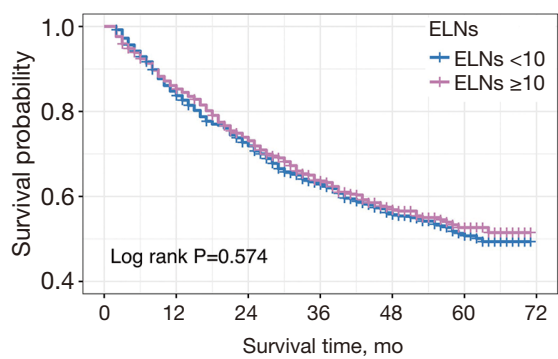

Number at risk

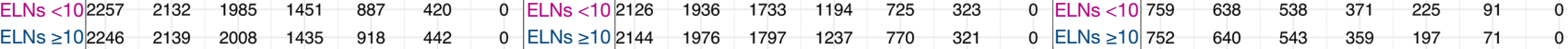

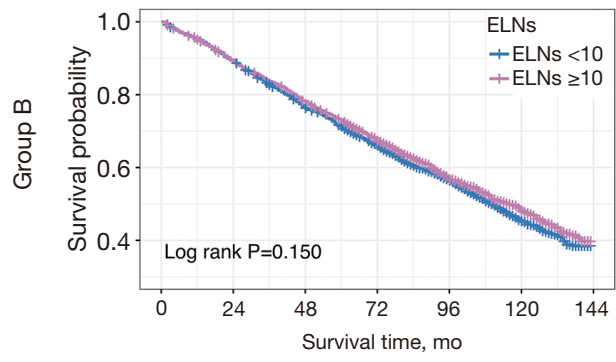

Number at risk

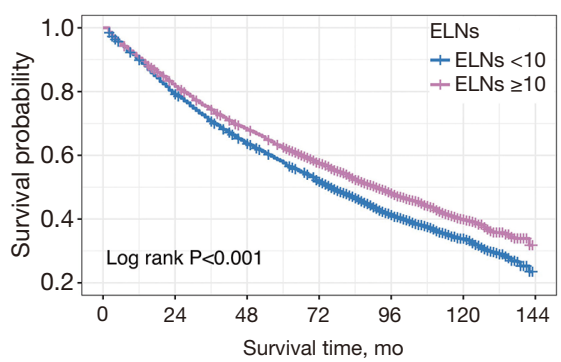

Number at risk

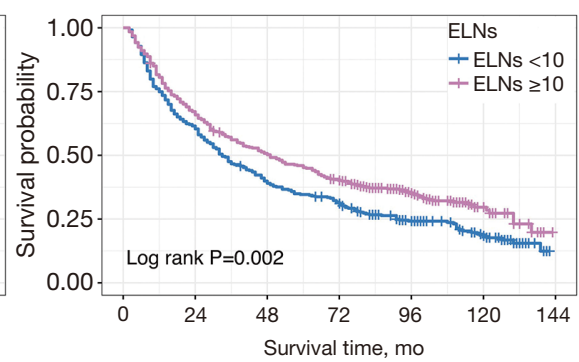

Number at risk

$\begin{array}{lllllllllllllllllllllllll}\text { ELNs }<10 & 2847 & 2543 & 2177 & 1856 & 1036 & 399 & 0 & \text { ELNs }<10 & 3158 & 2514 & 2014 & 1618 & 858 & 362 & 0 & \text { ELNs }<10 & 343 & 211 & 136 & 106 & 61 & 28 & 0\end{array}$

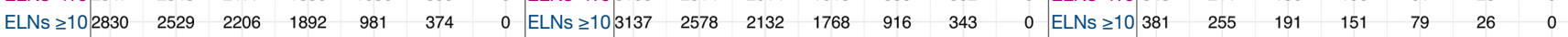

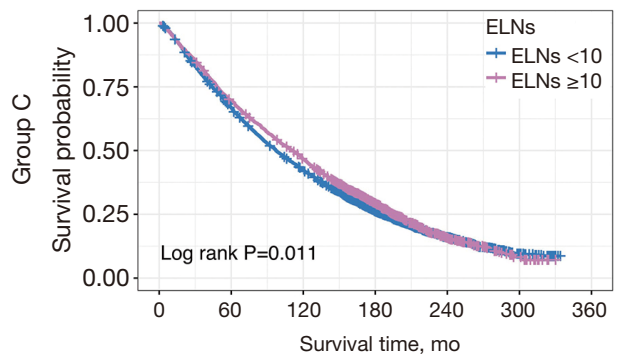

Number at risk

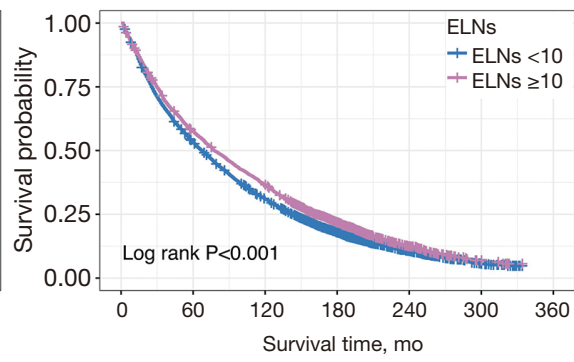

Number at risk

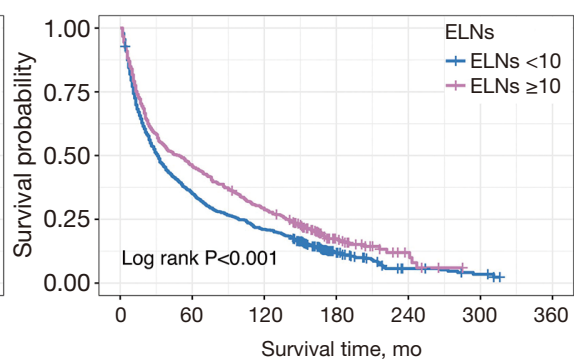

ElNs $<104714 \quad 3149-1990-767 \quad 230-44 \quad 007$ Number at risk

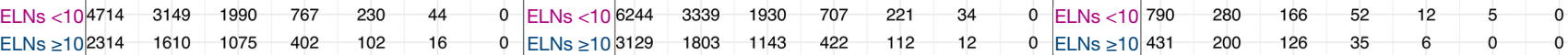

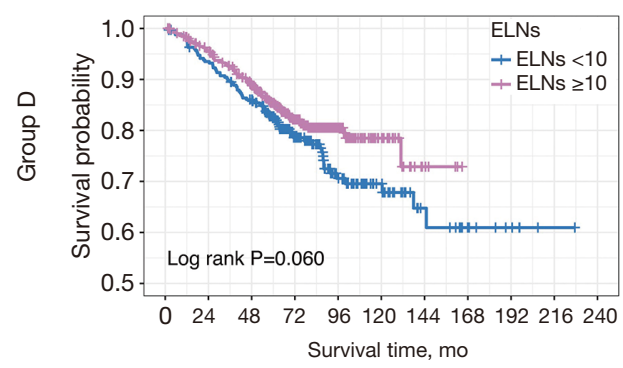

Number at risk

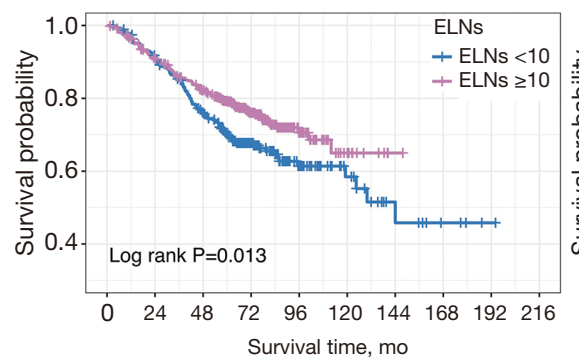

Number at risk

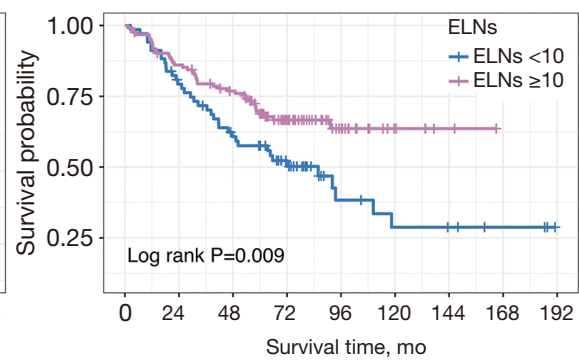

Number at risk

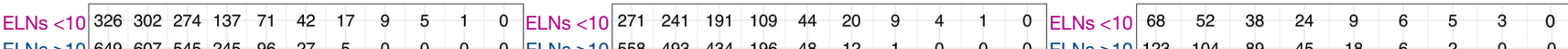

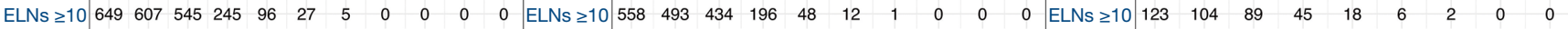

Figure 2 Kaplan-Meier survival curves of overall survival was stratified by T1, T2, and T3 in patients with ELNs $<10$ and ELNs $\geq 10$. ELNs, examined lymph nodes. 
A

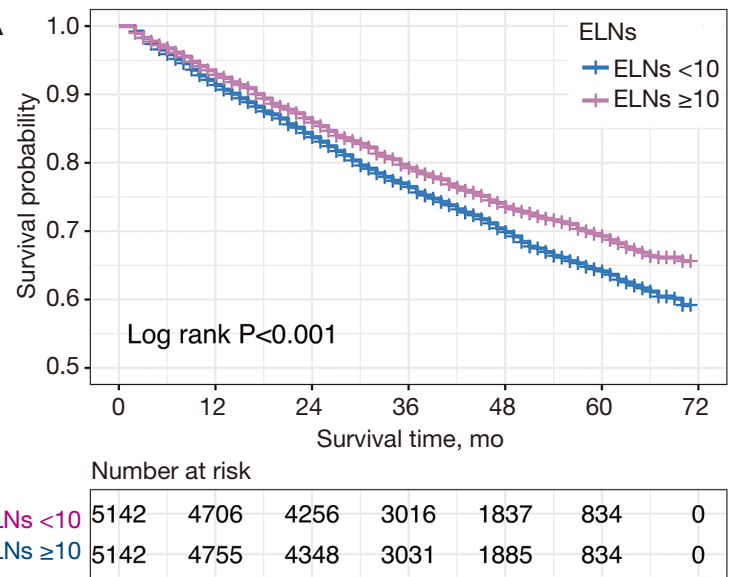

C

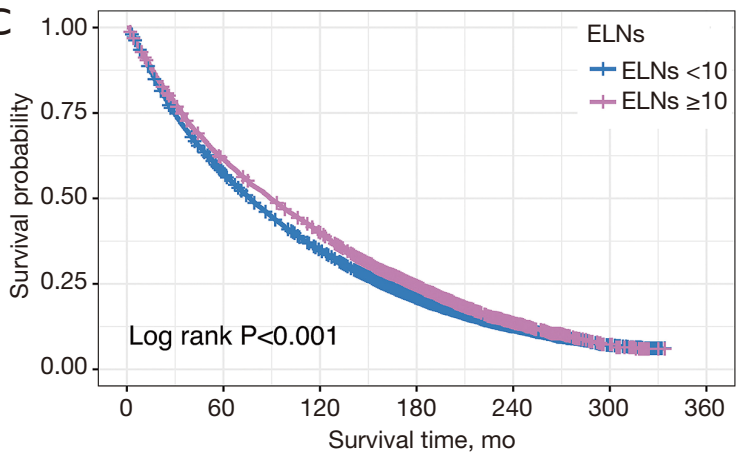

\begin{tabular}{|c|c|c|c|c|c|c|c|}
\hline \multirow[b]{2}{*}{ ELNs $<10$} & \multicolumn{7}{|c|}{ Number at risk } \\
\hline & 11748 & 6768 & 4086 & 1526 & 463 & 83 & 0 \\
\hline$E L N s \geq 10$ & 5874 & 3613 & 2344 & 859 & 220 & 28 & 0 \\
\hline
\end{tabular}

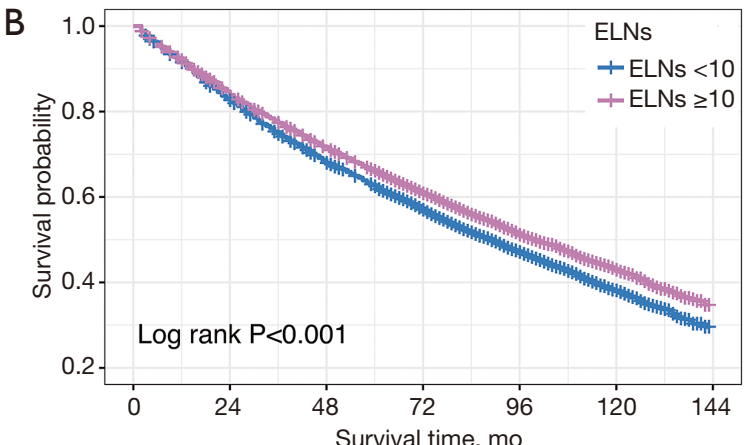

\begin{tabular}{|c|c|c|c|c|c|c|c|}
\hline \multirow[b]{2}{*}{ ELNs $<10$} & \multicolumn{7}{|c|}{ Number at risk } \\
\hline & 6348 & 5268 & 4327 & 3580 & 1955 & 789 & 0 \\
\hline ELNs $\geq 10$ & 6348 & 5362 & 4529 & 3811 & 1976 & 743 & 0 \\
\hline
\end{tabular}

$\mathrm{D}$

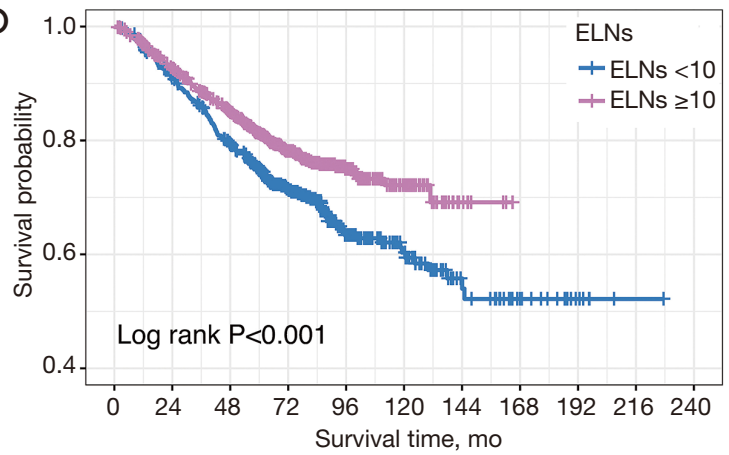

\begin{tabular}{|c|c|c|c|c|c|c|c|c|c|c|c|}
\hline \multirow[b]{2}{*}{ ELNs $<10$} & \multicolumn{11}{|c|}{ Number at risk } \\
\hline & 665 & 595 & 503 & 270 & 124 & 68 & 31 & 16 & 6 & 1 & 0 \\
\hline$E L N s \geq 10$ & 1330 & 1204 & 1068 & 486 & 162 & 45 & 8 & 0 & 0 & 0 & 0 \\
\hline
\end{tabular}

Figure 3 Kaplan-Meier survival curves of overall survival among Patients With ELNs $<10$ and ELNs $\geq 10$. (A) Kaplan-Meier survival curves of overall survival among patients with ELNs $<10$ and ELNs $\geq 10$ in group A; (B) Kaplan-Meier survival curves of overall survival among patients with ELNs $<10$ and ELNs $\geq 10$ in group B; (C) Kaplan-Meier survival curves of overall survival among patients with ELNs $<10$ and ELNs $\geq 10$ in group C; (D) Kaplan-Meier survival curves of overall survival among patients with ELNs $<10$ and ELNs $\geq 10$ in group D. ELNs, examined lymph nodes.

informed the thoroughness of clearance, which helped judging prognosis and accurate staging while providing guidance for adjuvant treatment and surveillance programs following treatment. Our results confirmed that 10 was the adequate lymph node cut-off number for dissection, while prognosis would not be improved with ELNs $>10$. At present, the research of lymph nodes was mainly divided into the location of lymph nodes and the number of lymph nodes. The former had relatively large number of studies, and its importance had been widely recognized. The latter was gaining attention with some studies supporting the importance of it $(12,14,18,19)$. Many guidelines recommended the number of minimum lymph nodes, but their recommended number varied greatly, which was likely to cause confusion in clinical practice. This is why we focused on the number of lymph nodes first rather than the location.

NCCN and International Association for the Study of Lung Cancer (IASLC) recommended a minimum of 6 ELNs in surgery for accurate staging, including 3 from the N1 station and 3 from the N2 station lymph nodes $(20,21)$. The European Society of Thoracic Surgery (ESTS) recommended a minimum of 6 pulmonary hilar or mediastinal lymph nodes (22). The Chinese Fournal of Oncology (2018 edition) recommended a minimum of 12 mediastinal and pulmonary lymph nodes, sampling or 
excising (23). The results of multiple studies revealed that the number of ELNs was correlated with long-term survival rate after curative surgery (9-15). The research of Liang et al. included 38,806 cases from the SEER database and 5,706 cases from Chinese multicenter database and recommended a minimum of 16 ELNs for NSCLC (16). However, the results of our study showed a minimum of 10 ELNs for $\mathrm{T}_{1-3} \mathrm{~N}_{0} \mathrm{M}_{0}$ patients is optimal. The differences in results could be related to the different staging, staging criteria, and years of the selected cases. Dr. Liang's modeling data was SEER $\mathrm{T}_{1-4} \mathrm{~N}_{0} \mathrm{M}_{0}$ patients from 2001 to 2008 (TNM staging from 6th edition), while our study used SEER $\mathrm{T}_{1-3} \mathrm{~N}_{0} \mathrm{M}_{0}$ patients from $2010 / 01 / 01$ to $2013 / 10 / 31$ (TNM staging from 7 th edition). Compared with 6 th edition, the 7 th edition changed multiple criteria (such as tumor sizes) which could affect the results. Dr. Liang used T4 data with late staging patients who could already have experienced severe spread and lymphatic metastasis, therefore additional ELN sampling was recommended. Our study reflected the meaning of ELNs in early stages of NSCLC surgery with more recent data representing the current status. We also used 16 as cut-off point in our modeling data and the results showed no difference in prognosis $(\mathrm{P}=1, \mathrm{RR}=1.03)$ (Table 1). Therefore, we considered the minimum of 10 ELNs to have a wider practical application. This result also corresponded with the recommendations of American College of Surgeons Commission on Cancer (CoC) (24) and approximated the suggestions of Samayoa et al. (25) [98,970 cases from the National Cancer Data Base (NCDB) in 2016). These similar outcomes from studies using different databases (NCDB and SEER) enhanced the reliability of our results. We have also included data from Chinese multicenter database to include an Asian population, which was low in proportion in both SEER and NCDB. For this, we considered our study to be more complete and represent more universal results. Finally, our patients had early staging and lymph nodes that were negative, which would help guide the early lung cancer treatment.

Our study is the largest retrospective study of stage $\mathrm{T}_{1-3} \mathrm{~N}_{0} \mathrm{M}_{0}$ patients known. The results of our study demonstrated that ELNs number in early NSCLC treatment was correlated with prognosis, and recommended a minimum of 10 ELNs for optimum patient outcome. Several possible theoretical bases have been considered for this conclusion: (I) patients would have higher risk of recurrence with inadequate ELNs which might not cover the metastasized lymph nodes. (II) With inadequate ELNs, N1 and N2 patients could be misdiagnosed as
N0 who would not receive chemotherapy and stricter surveillance programs following treatment, resulting in worse prognosis. However, the 3 SEER groups in this study all had qualification rates below $50 \%$ when 10 ELNs was used as a minimum standard. At the same time, only 2 in 11 Chinese centers had qualification rates over $80 \%$. The research of Smeltzer et al. demonstrated that $60 \%$ of the intrapulmonary lymph nodes were discarded in lobectomy specimens without examination (26). If surgeons or pathologists can examine the discarded lymph nodes, it is easy to raise the ELNs to 10 or more. We believe that if all the cases could reach the 10 ELN resection standard, patients' 5 -year survival rate could be greatly improved.

Some people have noted that additional resection of ELNs could increase the difficulty of surgery and increase potential risk of complications, which might have a negative influence on prognosis. According to the ACOSOG-Z0030 study, systematic lymph node sampling would only prolong surgical time and increase the amount of bleeding, not increase postoperative hospital stays, survival rates, and postoperative complications (27). Therefore, we consider that additional ELNs would not worsen patients' prognosis and allow for thorough clearance and better staging.

There were several limitations inherent in any study design that involves nonrandomized observational data (including biases and potential confounding variables). Firstly, the caliper value of many groups in this trial was too small, resulting in an overmatch problem. Secondly, the alternative biological hypothesis of the outcome differences in resected node-negative NSCLCs was not tested. Thirdly, part of the lymph nodes were broken because of the fusion or intraoperative and postoperative operations, which led to inaccurate counting of lymph nodes. Therefore, a multi-center prospective randomized controlled trial is expected in the future to minimize these limitations. Thirdly, the selected SEER cases failed to cover all states in the US, which may lead to bias and should be analyzed in combination with cases from other data bases. Lastly, our study only focused on the number of lymph node with exclusion of the location of lymph node which could be more important. We would like to analyze the location in the future in part II.

Our study discovered that ELNs number was correlated with prognosis and patients' survival rates, demonstrating the most significant differences when 10 ELNs was used as the minimum standard. Therefore, we recommended a minimum of 10 ELNs for $T_{1-3} N_{0} M_{0}$ patients for optimum survival benefit. 


\section{Acknowledgments}

We sincerely express our gratitude to Christian Paul and Hui Zhu for their providing language help.

Funding: This article was supported by Medical Scientific Research Foundation of Guangdong Province (A2017356) and Science and Technology Planning Project of Guangdong Province, China (2017A020219009).

\section{Footnote}

Reporting Checklist: The authors have completed the STROBE reporting checklist. Available at http://dx.doi. org/10.21037/tlcr-20-1024

Data Sharing Statement: Available at http://dx.doi. org/10.21037/tlcr-20-1024

Conflicts of Interest: All authors have completed the ICMJE uniform disclosure form (available at http://dx.doi. org/10.21037/tlcr-20-1024). The authors have no conflicts of interest to declare.

Ethical Statement: The authors are accountable for all aspects of the work in ensuring that questions related to the accuracy or integrity of any part of the work are appropriately investigated and resolved. The study was conducted in accordance with the Declaration of Helsinki (as revised in 2013). The study was approved by committee board of 11 participating institutions and individual consent for this retrospective analysis was waived (NO. 2019-0810)

Open Access Statement: This is an Open Access article distributed in accordance with the Creative Commons Attribution-NonCommercial-NoDerivs 4.0 International License (CC BY-NC-ND 4.0), which permits the noncommercial replication and distribution of the article with the strict proviso that no changes or edits are made and the original work is properly cited (including links to both the formal publication through the relevant DOI and the license). See: https://creativecommons.org/licenses/by-nc-nd/4.0/.

\section{References}

1. Siegel RL, Miller KD, Jemal A. Cancer statistics, 2019. CA Cancer J Clin 2019;69:7-34.

2. Goldstraw P, Chansky K, Crowley J, et al. The IASLC Lung Cancer Staging Project: Proposals for Revision of the TNM Stage Groupings in the Forthcoming (Eighth)

Edition of the TNM Classification for Lung Cancer. J

Thorac Oncol 2016;11:39-51.

3. D'Cunha J, Herndon JE, Herzan DL, et al. Poor correspondence between clinical and pathologic staging in stage 1 non-small cell lung cancer: results from CALGB 9761, a prospective trial. Lung Cancer 2005;48:241-6.

4. Smeltzer MP, Faris NR, Ray MA, et al. Association of Pathologic Nodal Staging Quality With Survival Among Patients With Non-Small Cell Lung Cancer After Resection With Curative Intent. JAMA Oncol 2018;4:80-7.

5. Thomas PA. Intraoperative lymph-node assessment during NSCLC surgery: the need for standardisation and quality evaluation. Lancet Oncol 2019;20:23-5.

6. National Comprehensive Cancer Network: NCCN clinical practice guidelines in oncology: Gastric cancer, V.2.2013. Available online: https://www.nccn.org/professionals/ physician_gls/pdf/gastric.pdf

7. National Comprehensive Cancer Network: NCCN clinica lpractice guidelines in oncology: Colorectal Cancer, V.2.2013. Available online: https://www.nccn.org/ professionals/physician_gls/pdf/colon.pdf

8. Rusch VW, Asamura H, Watanabe H, et al. The IASLC lung cancer staging project: a proposal for a new international lymph node map in the forthcoming seventh edition of the TNM classification for lung cancer. J Thorac Oncol 2009;4:568-77.

9. Gajra A, Newman N, Gamble GP, et al. Effect of number of lymph nodes sampled on outcome in patients with stage I non-small-cell lung cancer. J Clin Oncol 2003;21:1029-34.

10. Ludwig MS, Goodman M, Miller DL, et al. Postoperative survival and the number of lymph nodes sampled during resection of node-negative non-small cell lung cancer. Chest 2005;128:1545-50.

11. Fukui T, Mori S, Yokoi K, et al. Significance of the number of positive lymph nodes in resected non-small cell lung cancer. J Thorac Oncol 2006;1:120-5.

12. Ou SH, Zell JA. Prognostic significance of the number of lymph nodes removed at lobectomy in stage IA non-small cell lung cancer. J Thorac Oncol 2008;3:880-6.

13. Bria E, Milella M, Sperduti I, et al. A novel clinical prognostic score incorporating the number of resected lymph-nodes to predict recurrence and survival in nonsmall-cell lung cancer. Lung Cancer 2009;66:365-71.

14. Saji H, Tsuboi M, Yoshida K, et al. Prognostic impact of number of resected and involved lymph nodes at complete resection on survival in non-small cell lung cancer. J Thorac Oncol 2011;6:1865-71. 
15. Wei S, Asamura H, Kawachi R, et al. Which is the better prognostic factor for resected non-small cell lung cancer: the number of metastatic lymph nodes or the currently used nodal stage classification? J Thorac Oncol 2011;6:310-8.

16. Liang W, He J, Shen Y, et al. Impact of Examined Lymph Node Count on Precise Staging and Long-Term Survival of Resected Non-Small-Cell Lung Cancer: A Population Study of the US SEER Database and a Chinese MultiInstitutional Registry. J Clin Oncol 2017;35:1162-70.

17. Camp RL, Dolled-Filhart M, Rimm DL. X-tile: a new bio-informatics tool for biomarker assessment and outcome-based cut-point optimization. Clin Cancer Res 2004;10:7252-9.

18. Becker DJ, Levy BP, Gold HT, et al. Influence of Extent of Lymph Node Evaluation on Survival for Pathologically Lymph Node Negative Non-Small Cell Lung Cancer. Am J Clin Oncol 2018;41:820-5.

19. Osarogiagbon RU, Ogbata O, Yu X. Number of lymph nodes associated with maximal reduction of long-term mortality risk in pathologic node-negative non-small cell lung cancer. Ann Thorac Surg 2014;97:385-93.

20. National Comprehensive Cancer Network: NCCN clinical practice guidelines in oncology: Non-small cell lung cancer, V.1.2019. Available online: https://www.nccn. org/professionals/physician_gls/pdf/nsclc.pdf

21. Asamura H, Chansky K, Crowley J, et al. The International Association for the Study of Lung Cancer Lung Cancer Staging Project: Proposals for the Revision of the N Descriptors in the Forthcoming 8th Edition of

Cite this article as: Zhu Z, Song Z, Jiao W, Mei W, Xu C, Huang Q, An C, Shi J, Wang W, Yu G, Sun P, Zhang Y, Shen J, Song Y, Qian J, Yao W, Yang H; written on behalf of AME Lung Cancer Collaborative Group. A large real-world cohort study of examined lymph node standards for adequate nodal staging in early non-small cell lung cancer. Transl Lung Cancer Res 2021;10(2):815-825. doi: 10.21037/tlcr-20-1024 the TNM Classification for Lung Cancer. J Thorac Oncol 2015;10:1675-84.

22. De Leyn P, Dooms C, Kuzdzal J, et al. Revised ESTS guidelines for preoperative mediastinal lymph node staging for non-small-cell lung cancer. Eur J Cardiothorac Surg 2014;45:787-98.

23. Chinese Medical Association, Oncology Branch of Chinese Medical Association, Journal of Chinese Medical Association. Chinese medical association guidelines for clinical diagnosis and treatment of lung cancer (2018th). Chinese Journal of Oncology 2018;40:935-64.

24. American College of Surgeons. CoC Quality of Care Measures. CoC Measures for Quality of Cancer Care. Available online: https://www.facs.org/qualityprograms/ cancer/ncdb/quality-measures. Posted Fall 2014. Accessed August 20, 2017.

25. Samayoa AX, Pezzi TA, Pezzi CM, et al. Rationale for a Minimum Number of Lymph Nodes Removed with Non-Small Cell Lung Cancer Resection: Correlating the Number of Nodes Removed with Survival in 98,970 Patients. Ann Surg Oncol 2016;23:1005-11.

26. Smeltzer MP, Faris N, Yu XH, et al. Missed Intrapulmonary Lymph Node Metastasis and Survival After Resection of Non-Small Cell Lung Cancer. Ann Thorac Surg 2016;102:448-53.

27. Osarogiagbon RU, Decker PA, Ballman K, et al. Survival Implications of Variation in the Thoroughness of Pathologic Lymph Node Examination in American College of Surgeons Oncology Group Z0030 (Alliance). Ann Thorac Surg 2016;102:363-9. 


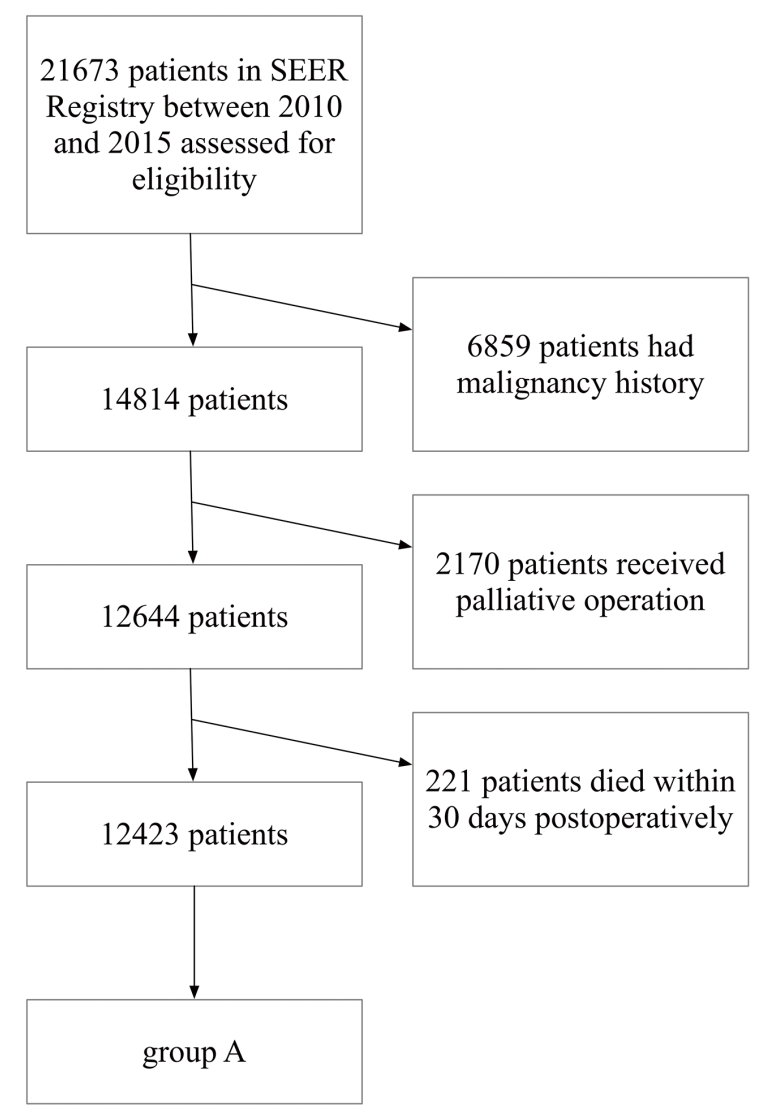

Figure S1 Diagram of group A selection steps. SEER, Surveillance, Epidemiology, and End Results.

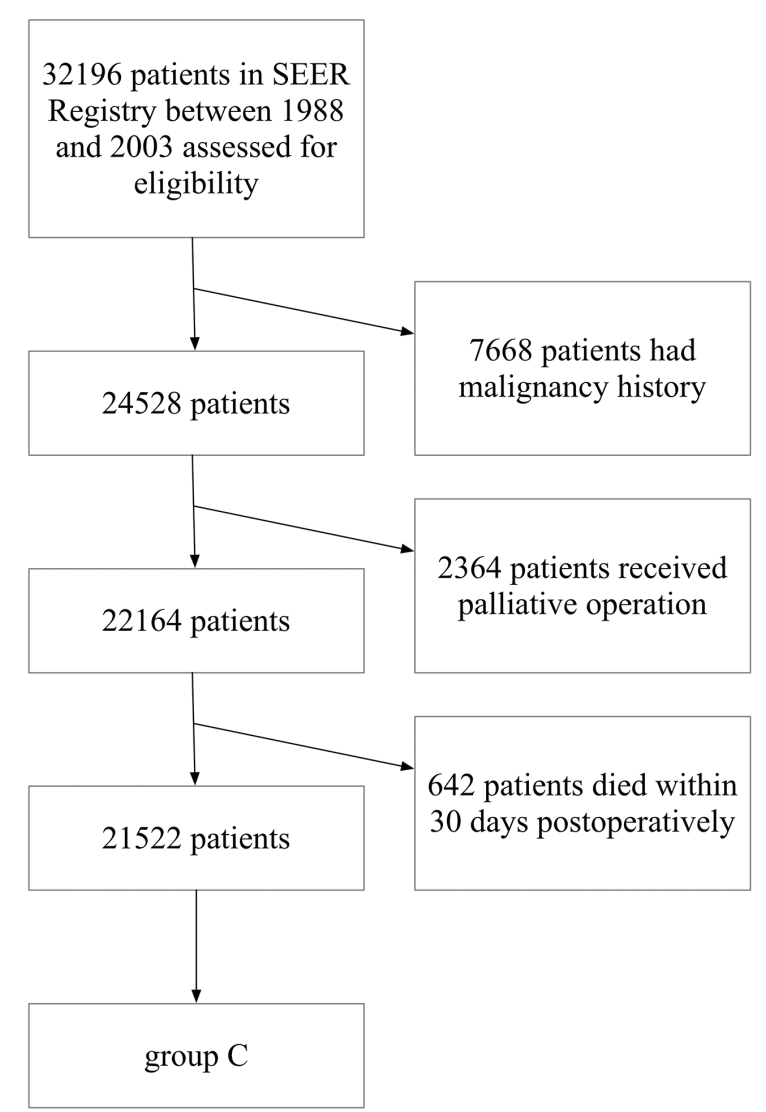

Figure S3 Diagram of group C selection steps. SEER, Surveillance, Epidemiology, and End Results.

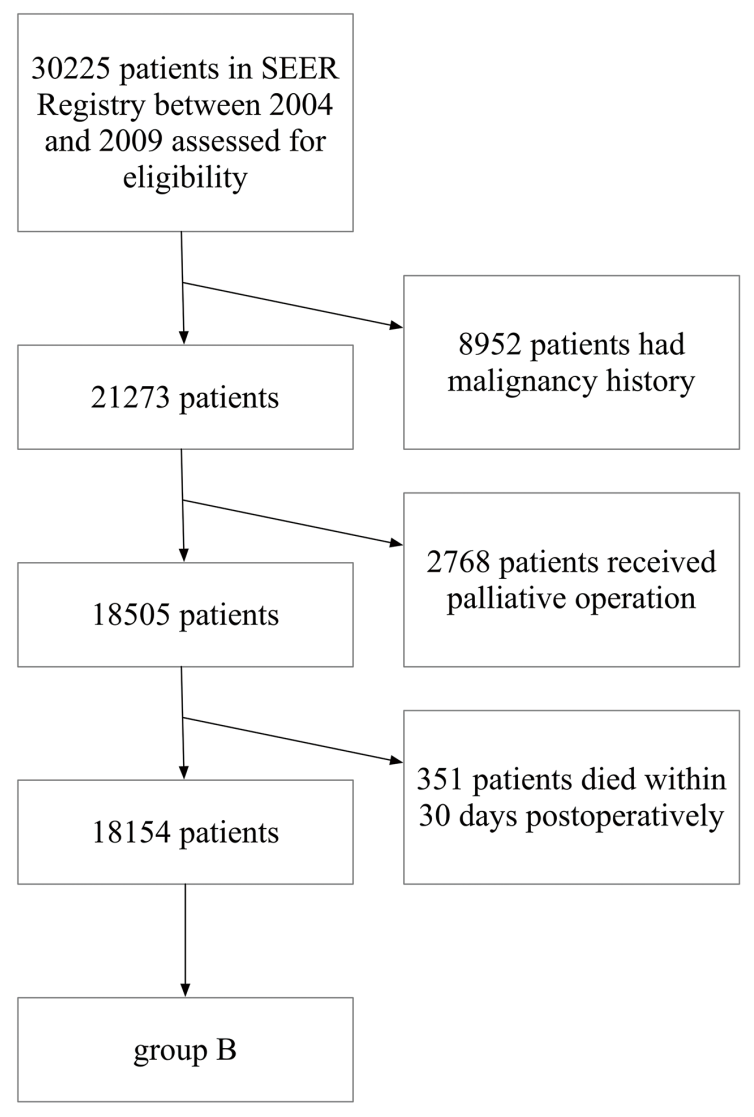

Figure S2 Diagram of group B selection steps. SEER, Surveillance, Epidemiology, and End Results. 


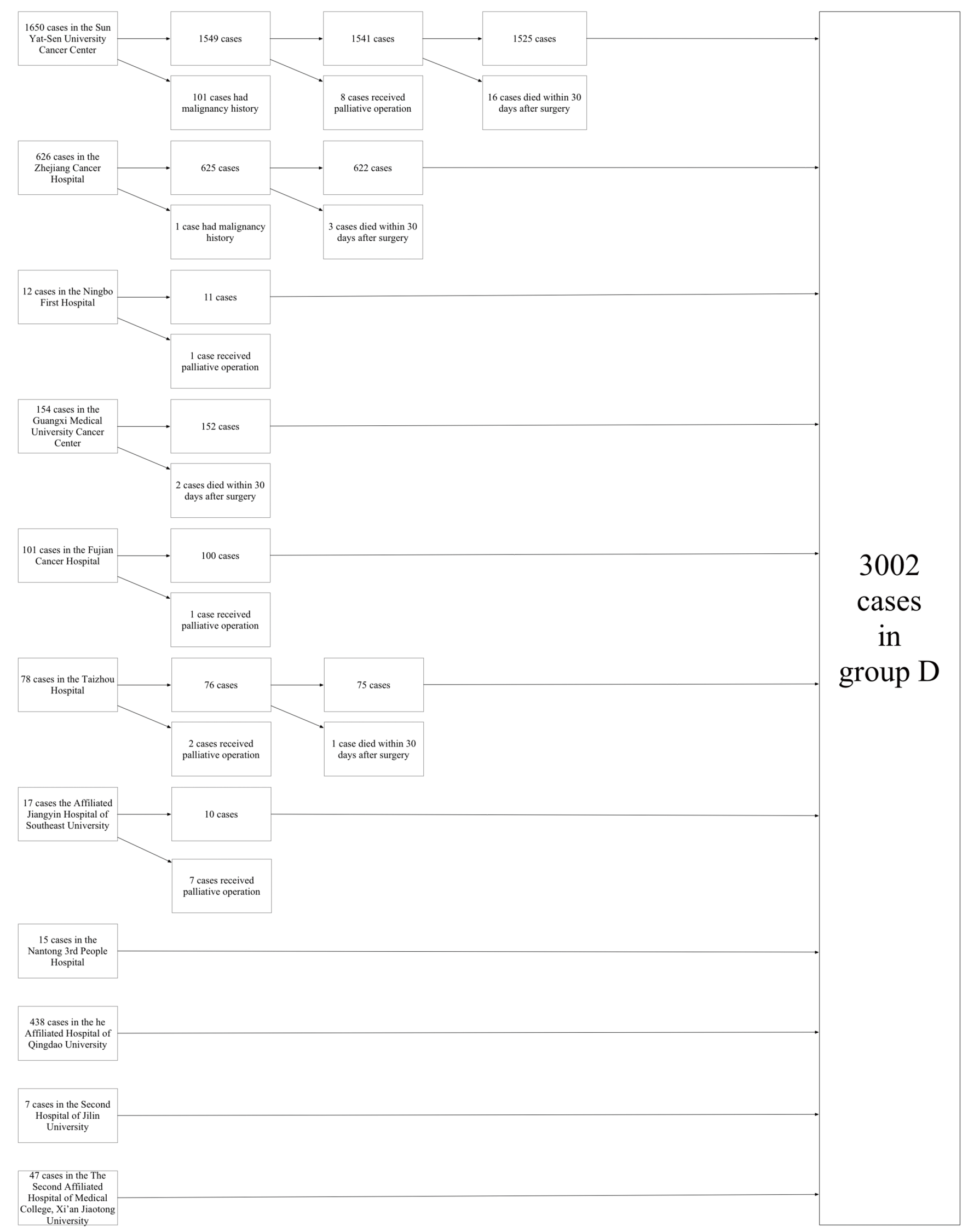

Figure S4 Diagram of group D selection steps.

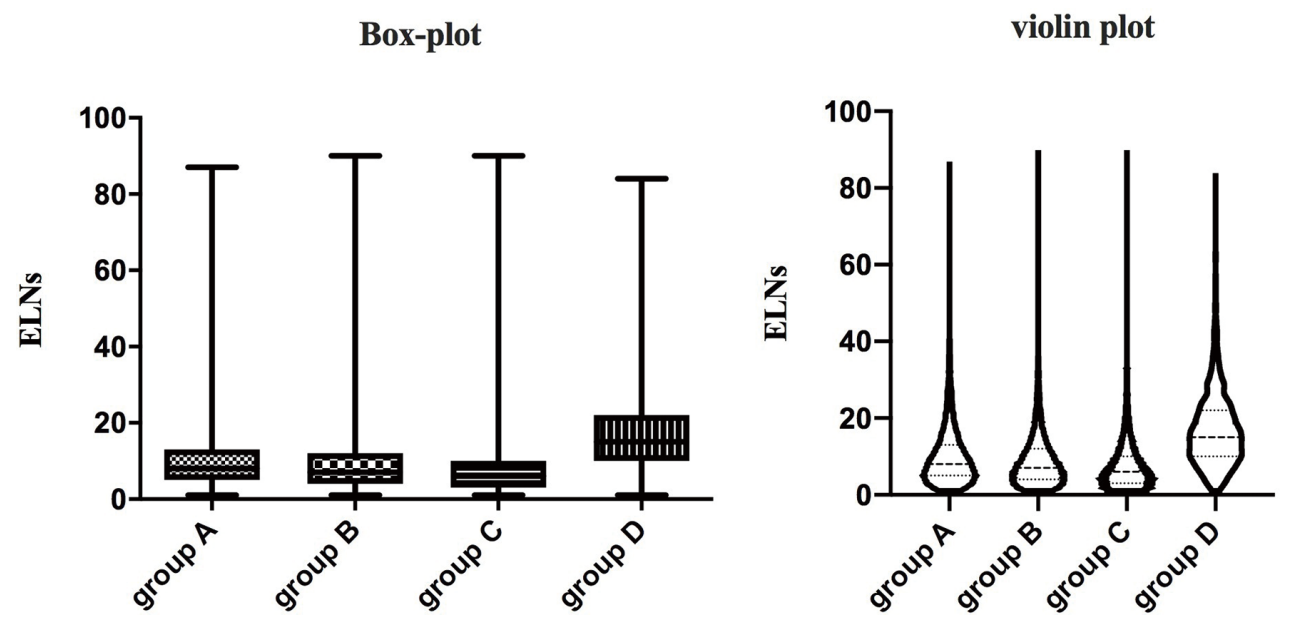

Figure S5 The examined lymph nodes of the entire study. ELNs, examined lymph nodes. 
Table S1 Patient characteristics of the entire study

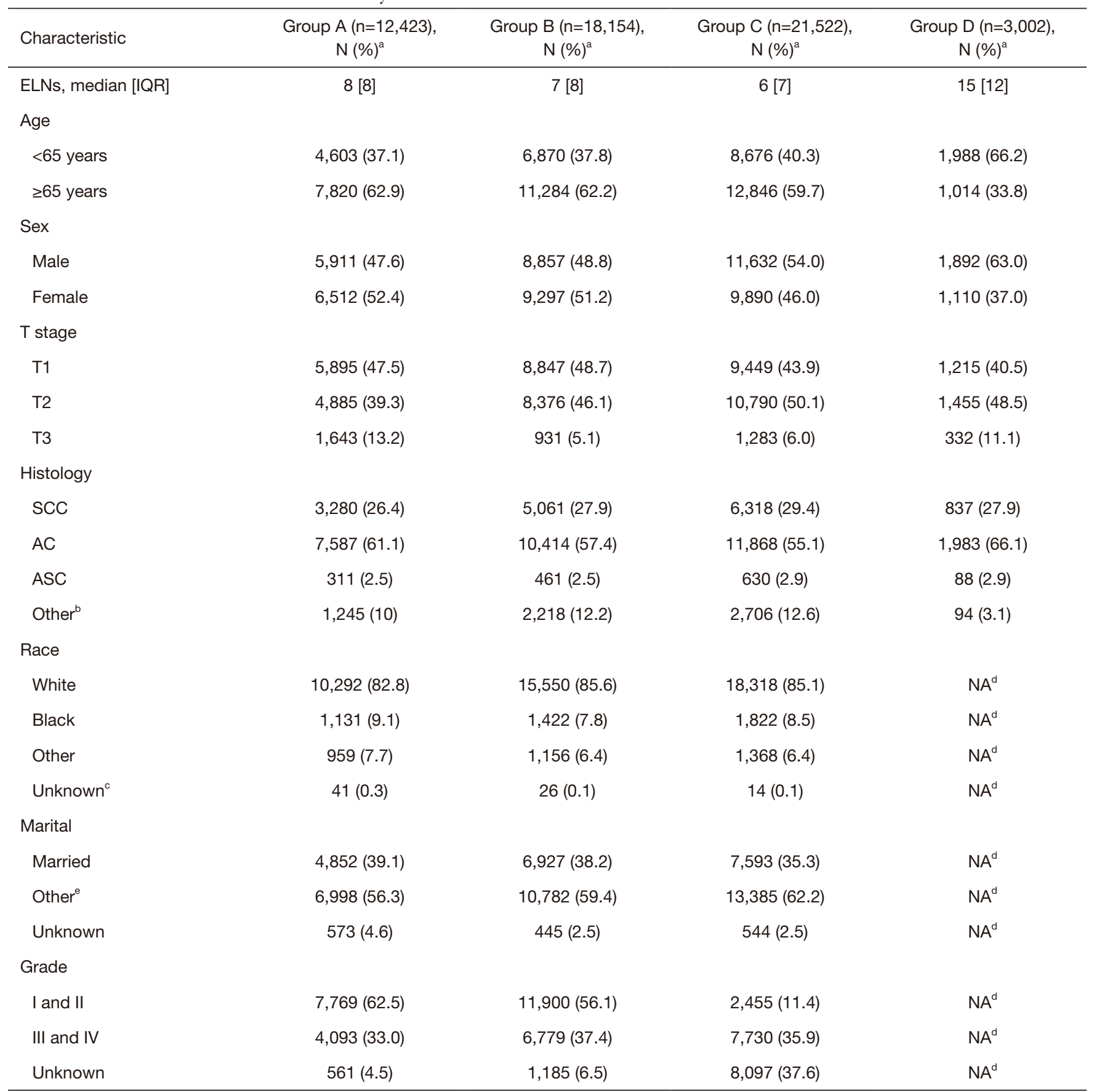

a , percentages might not add up to $100 \%$ due to approximation; ${ }^{b}$, non-small cell not further defined; ${ }^{c}$, includes American Indian, Chinese, Japanese and other specified types of races; ${ }^{d}$, race, marriage, and grade are not included in Chinese multi-institutional registry; ${ }^{e}$, includes single (never married), separated, divorced, widowed and unmarried or domestic partner. ELNs, examined lymph nodes; IQR, interquartile; SCC, squamous cell carcinoma; AC, adenocarcinoma; ASC, adenosquamous carcinoma; NA, not available. 
Table S2 Patient characteristics (before PSM)

\begin{tabular}{|c|c|c|c|c|c|c|c|c|}
\hline Characteristic & \multicolumn{3}{|c|}{ Group B, N (\%) } & \multicolumn{3}{|c|}{ Group C, N (\%) } & \multicolumn{2}{|c|}{ Group D, N (\%) } \\
\hline$<65$ years & 4,437 (37.6) & 2,433 (38.3) & & $6,240(39.9)$ & $2,436(41.5)$ & & $414(62.3)$ & $1,574(67.4)$ \\
\hline Male & $5,679(48.1)$ & $3,178(50.1)$ & & $8,304(53.1)$ & $3,328(56.7)$ & & $397(59.7)$ & $1,495(64.0)$ \\
\hline Female & 6,127 (51.9) & 3,170 (49.9) & & $7,344(46.9)$ & $2,546(43.3)$ & & 268 (40.3) & $842(36.0)$ \\
\hline T stage & & & 0.000 & & & 0.000 & & \\
\hline Histology & & & 0.000 & & & 0.000 & & \\
\hline SCC & $3,130(26.5)$ & $1,931(30.4)$ & & 4,369 (27.9) & 1,949 (33.2) & & $147(22.1)$ & 690 (29.5) \\
\hline$A C$ & 6,937 (58.8) & 3,477 (54.8) & & $8,832(56.4)$ & $3,036(51.7)$ & & $470(70.7)$ & $1,513(64.7)$ \\
\hline SAC & $306(2.6)$ & $155(2.4)$ & & $455(2.9)$ & $175(3.0)$ & & $24(3.6)$ & $64(2.7)$ \\
\hline Other $^{\mathrm{b}}$ & $1,433(12.1)$ & $785(12.4)$ & & 1,992 (12.7) & $714(12.2)$ & & $24(3.6)$ & $70(3.0)$ \\
\hline Race & & & 0.000 & & & 0.000 & & \\
\hline White & $\begin{array}{c}10,014 \\
(84.8)\end{array}$ & $5,536(87.2)$ & & $\begin{array}{c}13,205 \\
(84.4)\end{array}$ & $5,113(87)$ & & $N A^{d}$ & $N A^{d}$ \\
\hline Married & $4,546(38.5)$ & $2,381(37.5)$ & & $5,640(36.0)$ & 1,953 (33.2) & & $N A^{d}$ & $N A^{d}$ \\
\hline Other $^{\mathrm{e}}$ & $6,956(58.9)$ & $3,826(60.3)$ & & $9,626(61.5)$ & $3,759(64.0)$ & & $N A^{d}$ & $N A^{d}$ \\
\hline Unknown & 304 (2.6) & $141(2.2)$ & & $382(2.4)$ & $162(2.8)$ & & $N A^{d}$ & $N A^{d}$ \\
\hline Grade & & & 0.000 & & & 0.000 & & \\
\hline I and II & $6,745(57.1)$ & $3,445(54.3)$ & & $7,416(47.4)$ & $2,769(47.1)$ & & $N A^{d}$ & $N A^{d}$ \\
\hline III and IV & $4,281(36.3)$ & 2,498 (39.4) & & 6,588 (42.1) & $2,617(44.6)$ & & $N A^{d}$ & $N A^{d}$ \\
\hline Unknown & $780(6.6)$ & $405(6.4)$ & & $1,644(10.5)$ & 488 (8.3) & & $N A^{d}$ & $N A^{d}$ \\
\hline
\end{tabular}

${ }^{\text {a }}$, percentages might not add up to $100 \%$ due to approximation; ${ }^{b}$, non-small cell not further defined; ${ }^{c}$, includes American Indian, Chinese, Japanese and other specified types of races; ${ }^{d}$, race, marriage, and grade are not included in Chinese multi-institutional registry; ${ }^{\text {, }}$ includes single (never married), separated, divorced, widowed and unmarried or domestic partner. ELNs, examined lymph nodes; SCC, squamous cell carcinoma; AC, adenocarcinoma; ASC, adenosquamous carcinoma; NA, not available. 
Table S3 Patient characteristics (after PSM)

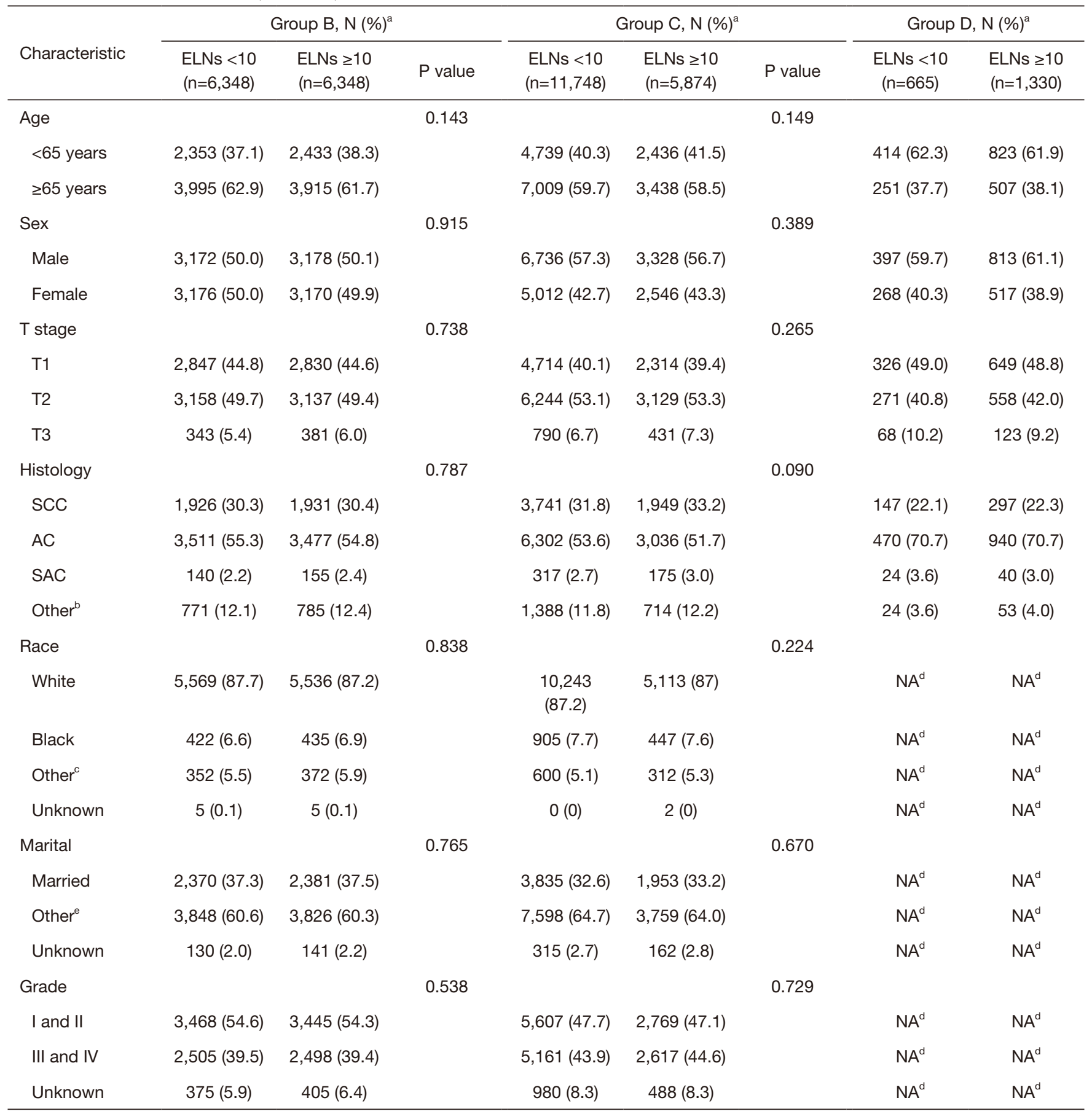

${ }^{\text {a }}$, percentages might not add up to $100 \%$ due to approximation; ${ }^{b}$, non-small cell not further defined; ${ }^{c}$, Includes American Indian, Chinese, Japanese and other specified types of races; ' , race, marriage, and grade are not included in Chinese multi-institutional registry; ${ }^{\text {, }}$ includes single (never married), separated, divorced, widowed and unmarried or domestic partner. ELNs, examined lymph nodes; IQR, interquartile; SCC, squamous cell carcinoma; AC, adenocarcinoma; ASC, adenosquamous carcinoma; NA, not available. 
Table S4 Cox proportional hazard multivariable analysis results for entire study

\begin{tabular}{|c|c|c|c|c|c|c|c|c|}
\hline Characteristic & \multicolumn{3}{|c|}{ Group B, N (\%) } & \multicolumn{3}{|c|}{ Group C, N (\%) } & \multicolumn{2}{|c|}{ Group D, N (\%) } \\
\hline$<65$ years & 4,437 (37.6) & $2,433(38.3)$ & & $6,240(39.9)$ & $2,436(41.5)$ & & $414(62.3)$ & $1,574(67.4)$ \\
\hline Male & $5,679(48.1)$ & $3,178(50.1)$ & & $8,304(53.1)$ & $3,328(56.7)$ & & $397(59.7)$ & $1,495(64.0)$ \\
\hline Female & 6,127 (51.9) & $3,170(49.9)$ & & $7,344(46.9)$ & 2,546 (43.3) & & $268(40.3)$ & $842(36.0)$ \\
\hline T stage & & & 0.000 & & & 0.000 & & \\
\hline Histology & & & 0.000 & & & 0.000 & & \\
\hline SCC & $3,130(26.5)$ & $1,931(30.4)$ & & 4,369 (27.9) & 1,949 (33.2) & & $147(22.1)$ & $690(29.5)$ \\
\hline$A C$ & 6,937 (58.8) & $3,477(54.8)$ & & $8,832(56.4)$ & $3,036(51.7)$ & & $470(70.7)$ & $1,513(64.7)$ \\
\hline SAC & $306(2.6)$ & $155(2.4)$ & & $455(2.9)$ & $175(3.0)$ & & $24(3.6)$ & $64(2.7)$ \\
\hline Other $^{b}$ & $1,433(12.1)$ & 785 (12.4) & & 1,992 (12.7) & 714 (12.2) & & $24(3.6)$ & $70(3.0)$ \\
\hline Race & & & 0.000 & & & 0.000 & & \\
\hline White & $\begin{array}{c}10,014 \\
(84.8)\end{array}$ & $5,536(87.2)$ & & $\begin{array}{c}13,205 \\
(84.4)\end{array}$ & $5,113(87.0)$ & & $N A^{d}$ & $N A^{d}$ \\
\hline Married & 4,546 (38.5) & $2,381(37.5)$ & & $5,640(36.0)$ & 1,953 (33.2) & & $N A^{d}$ & $N A^{d}$ \\
\hline Other $^{e}$ & 6,956 (58.9) & $3,826(60.3)$ & & $9,626(61.5)$ & $3,759(64)$ & & $N A^{d}$ & $N A^{d}$ \\
\hline Unknown & $304(2.6)$ & $141(2.2)$ & & $382(2.4)$ & $162(2.8)$ & & $N A^{d}$ & $N A^{d}$ \\
\hline Grade & & & 0.000 & & & 0.000 & & \\
\hline I and II & $6,745(57.1)$ & $3,445(54.3)$ & & $7,416(47.4)$ & $2,769(47.1)$ & & $N A^{d}$ & $N A^{d}$ \\
\hline III and IV & $4,281(36.3)$ & 2,498 (39.4) & & $6,588(42.1)$ & $2,617(44.6)$ & & $N A^{d}$ & $N A^{d}$ \\
\hline Unknown & $780(6.6)$ & 405 (6.4) & & $1,644(10.5)$ & 488 (8.3) & & $N A^{d}$ & $N A^{d}$ \\
\hline
\end{tabular}

${ }^{a}$, percentages might not add up to $100 \%$ due to approximation; ${ }^{b}$, non-small cell not further defined; ${ }^{\mathrm{c}}$, includes American Indian, Chinese, Japanese and other specified types of races; ${ }^{d}$, race, marriage, and grade are not included in Chinese multi-institutional registry; ${ }^{\text {, }}$ includes single (never married), separated, divorced, widowed and unmarried or domestic partner. HR, hazard ratio; ELNs, examined lymph nodes; SCC, squamous cell carcinoma; AC, adenocarcinoma; ASC, adenosquamous carcinoma; NA, not available. 